\title{
KEMAMPUAN CLINICAL REASONING PADA UJIAN OSCE MAHASISWA KEDOKTERAN TAHUN KETIGA
}

\author{
Diani Puspa Wijaya \\ Fakultas Kedokteran Universitas Islam Indonesia \\ Email: dianipuspa@yahoo.com
}

\begin{abstract}
Background : Clinical reasoning is one of the clinical skill competencies that must be owned by a doctor so it needs to be studied and tested. The OSCE is one method of assessment that can be used to assess the achievement of clinical reasoning. OSCE in the third year at Faculty of Medicine Islamic University of Indonesia (FM IUI) has been using clinical case OSCE so that can be used to assess clinical reasoning skill in addition to others clinical skills such as physical examination and clinical procedural skills. This study aimed to evaluate the clinical reasoning skills of students in the third year of the OSCE exam at FM IUI.

Methods : The cross sectional study method was used in this study. OSCE test result semesters 5 and 6 of the academic year 2015/2016 collected. Clinical reasoning skills of students in OSCE obtained from the score of the diagnosis ability in clinical case OSCE station. The difference between clinical reasoning skill on each OSCE station and its correlation with the written test on the corresponding block were analyzed.
\end{abstract}

Results: There is differences between clinical reasoning skill in OSCE stations semester 5 and 6. There was no relationship between the score clinical reasoning skills at the OSCE with written test achievement on the corresponding block.

Conclusion: The clinical reasoning skills on the OSCE semesters 5 and 6 do not illustrate the clinical reasoning skills of third-year medical students in this study. This study supports the need for further development of the assessment of clinical reasoning skills on the OSCE for medical students.

Keywords : clinical reasoning, OSCE, medical student

\begin{abstract}
ABSTRAK
Latar Belakang: Penalaran klinis atau clinical reasoning merupakan salah satu kompetensi keterampilan klinis yang harus dimiliki oleh seorang dokter sehingga perlu dipelajari dan diujikan. OSCE merupakan salah satu metode assessment yang dapat digunakan untuk menilai pencapaian clinical reasoning. OSCE pada tahun ketiga di FK UII telah menggunakan kasus klinis untuk dapat juga menilai clinical reasoning disamping keterampilan klinis yang lain seperti pemeriksaan fisik dan tindakan prosedural. Penelitian ini bertujuan mengevaluasi kemampuan clinical reasoning mahasiswa kedokteran pada ujian OSCE tahun ketiga di FK UII.

Metode : Metode yang digunakan adalah cross sectional dari hasil ujian OSCE semester 5 dan 6 tahun akademik 2015/2016. Kemampuan clinical reasoning mahasiswa pada ujian OSCE didapatkan dari nilai kemampuan menegakkan diagnosis pada stasion OSCE yang berupa manajemen kasus klinis. Nilai OSCE direkap pada semua mahasiswa yang mengikuti ujian pada periode tersebut. Analisis dilakukan
\end{abstract}


dengan melihat perbedaan kemampuan clinical reasoning antar station OSCE dan menilai korelasinya dengan ujian tulis pada blok yang bersesuain .

Hasil: Terdapat perbedaan kemampuan clinical reasoning antar stasion OSCE baik di semester ke 5 maupun ke 6 . Tidak terdapat hubungan antara nilai kemampuan diagnosis pada ujian OSCE dengan pencapaian nilai ujian tulis blok yang berkaitan dengan konten OSCE yang diujikan.

Kesimpulan: Kemampuan diagnosis pada ujian OSCE semester 5 dan 6 tidak menggambarkan kemampuan clinical reasoning mahasiswa tahun ketiga pada penelitian ini. Diperlukan evaluasi dan pengembangan lebih lanjut mengenai penilaian dan pencapaian kemampuan clinical reasoning pada ujian OSCE bagi mahasiswa kedokteran.

Kata kunci : clinical reasoning, OSCE, mahasiswa kedokteran

\section{PENDAHULUAN}

Kemampuan clinical reasoning termasuk dalam keterampilan klinis dasar yang penting dipelajari dalam proses pendidikan dokter. Seorang dokter harus mampu mensintesis, menarik kesimpulan, menginterpretasikan berbagai informasi klinis yang didapat dari pasien baik melalui history taking, pemeriksaan fisik dan hasil dari pemeriksaan penunjang yang dilakukan. Kemampuan clinical reasoning ini dikembangkan secara berkelanjutan dari proses pembelajaran baik di tahap pendidikan sarjana, pendidikan profesi maupun setelah menjadi praktisi medis. Kemampuan clinical reasoning didapat melalui pengetahuan dasar, pengalaman dan konteks dari kasus klinis. ${ }^{1,2}$

Telah banyak metode dikembangkan dalam pengajaran clinical reasoning, diantaranya adalah adalah pengembangan pembelajaran yang berbasis kepada kasus klinis. ${ }^{2}$ Fakultas Kedokteran UII (FK UII) mengembangkan salah satu bentuk pembelajaran berbasis kasus ini melalui kegiatan pembelajaran Integrated Patient Management (IPM). Sesi pembelajaran IPM dilakukan pada sesi pembelajaran keterampilan medik.
Mahasiswa akan mendapatkan skenario kasus klinik yang diperankan oleh pasien standar. Kasus klinis tersebut akan disertai dengan perintah untuk melakukan penggalian informasi terkait kasus klinis pasien, melakukan pemeriksaan fisik dan penunjang yang sesuai, menyampaikan diagnosis beserta rencana penatalaksanaan yang sesuai. Pada model pembelajaran ini mahasiswa akan memiliki kesempatan untuk menggali berbagai informasi dari pasien, mengembangkan hipotesis terkait masalah pada pasien, menginterpretasikan informasi yang ada pada pasien. Keterampilan-keterampilan yang merupakan bagian dari kemampuan clinical reasoning, sebagai kompetensi utama yang harus dimiliki sebagai seorang dokter nantinya. ${ }^{1}$

$$
\text { Metode assessment juga }
$$
merupakan aspek yang penting dalam pengembangan kemampuan clinical reasoning. Metode assessment yang tepat akan memberikan informasi yang baik bagi pengembangan kompetensi mahasiswa. Hasil dari proses assessment akan dapat memberikan informasi pencapaian mahasiswa mengenai materi yang diajarkan, sehingga akan memberikan 
feedback bagi institusi untuk pengembangan proses pembelajaran berikutnya. Objective Structured Clinical Examination (OSCE) merupakan salah satu bentuk assessment yang banyak digunakan untuk menilai kompetensi pada proses pembelajaran di kedokteran. Salah satunya, pada OSCE dapat dilakukan penilaian pada kemampuan clinical reasoning. ${ }^{3,4}$

\section{Multiple Choice Question (MCQ)} juga merupakan salah satu metode assessment yang sering digunakan dan valid untuk menilai kemampuan kognitif maupun clinical reasoning. ${ }^{5}$ Di FK UII, penilaian pencapaian mahasiswa terhadap konten blok dilakukan di akhir proses blok melalui ujian tulis dengan menggunakan soal MCQ dan MEQ. Pada penelitian ini mengevaluasi kemampuan clinical reasoning mahasiswa tahun ketiga FK UII sebagai hasil pembelajaran blok dan keterampilan medik dengan menggunakan metode IPM. Kemampuan clinical reasoning mahasiswa dilihat dari kemampuan menegakkan diagnosis pada ujian OSCE dengan kasus klinis beserta pencapaian mahasiswa pada ujian tulis blok.

\section{METODE}

Jenis penelitain yang digunakan pada penelitian ini adalah deskriptif kuantitatif, dan pada penelitian ini menggunakan rancangan cross sectional. Pada penelitian ini mendeskripsikan kemampuan clinical reasoning mahasiswa tahun ketiga FK UII pada ujian OSCE yang dinilai melalui kemampuan menegakkan diagnosis kasus klinis yang diberikan pada setiap stasion OSCE.

Populasi pada penelitian ini adalah mahasiswa tahun ketiga FK UII. Sampel pada penelitian ini adalah mahasiswa tahun ketiga FK UII pada tahun akademik 2015/2016 yang mengikuti ujian OSCE semester 5 dan 6 . Pengambilan sampel pada penelitain ini ditentukan dengan teknik total sampling.

Perbandingan kemampuan clinical reasoning antar station OSCE dievaluasi dengan uji beda lebih dari 2 kelompok menggunakan program olah data SPSS dikarenakan terdapat lebih dari 2 stasion ujian OSCE yang menilai kemampuan diagnosis pada OSCE semester 5 dan 6 . Kemampuan clinical reasoning pada ujian OSCE juga dianalisis korelasinya dengan pencapaian kognitif mahasiswa yang didapatkan melalui pencapaian nilai ujian blok yang bersesuai dengan materi atau kasus OSCE yang diujikan.

\section{HASIL}

Pada kurikulum tahun ketiga FK UII dengan tema fase Manajamen Masalah Kesehatan, terdapat 3 blok pada semester 5 dan 3 blok pada semester 6 . Blok tersebut adalah Blok Masalah Kehamilan dan Reproduksi (3.1), Blok Masalah Pada Anak (3.2), Blok Masalah Pada Remaja (3.3), Blok masalah Dewasa I (3.4), Blok Masalah Pada Dewasa II (3.5) serta Blok Masalah Pada Usia Lanjut (3.6). Ujian OSCE dilaksnakan disetiap akhir masingmasing semester. Terdapat 106 mahasiswa yang mengikuti ujian OSCE semester 5 dan 6 pada tahun akademik 2015/2016. Terdiri 
atas 62 mahasiswa dengan jenis kelamin perempuan $(58,41 \%)$ dan 44 mahasiswa dengan jenis kelamin laki-laki (41,59\%). Ujian OSCE pada semester 5 terdiri atas 11 stasion dengan 4 stasion merupakan OSCE yang menggunakan kasus klinis (Integrated Patient Management (IPM)) dan 7 stasion keterampilan klinis prosedural (Tabel 1).
Sementara pada ujian OSCE semester 6 terdapat 10 stasion OSCE yang kesemuanya merupakan OSCE yang menggunakan kasus klinis dengan pendekatan sistem (Tabel 2). Materi ujian OSCE tersebut berkesesuaian dengan materi blok yang berjalan di semester 5 dan 6.

Tabel 1. Materi OSCE semester 5 dan blok yang bersesuaian

\begin{tabular}{|c|c|c|c|}
\hline No & Materi OSCE Semester 5 & \multicolumn{2}{|c|}{ Blok Yang Bersesuaian } \\
\hline 1 & IPM 1 (Gynekologi) & \multicolumn{2}{|c|}{ Blok 3.1} \\
\hline 2 & Konseling KB & \multicolumn{2}{|c|}{ Blok 3.1} \\
\hline 3 & Pertolongan Persalinan & \multicolumn{2}{|c|}{ Blok 3.1} \\
\hline 4 & Antenatal Care & \multicolumn{2}{|c|}{ Blok 3.1} \\
\hline 5 & Implant & \multicolumn{2}{|c|}{ Blok 3.1} \\
\hline 6 & IPM 2 (Pediatrik 1) & \multicolumn{2}{|c|}{ Blok 3.2} \\
\hline 7 & IPM 3 (Pediatrik 2) & \multicolumn{2}{|c|}{ Blok 3.2} \\
\hline 8 & Resusitasi Neonatus & \multicolumn{2}{|c|}{ Blok 3.2} \\
\hline 9 & Sirkumsisi & \multicolumn{2}{|c|}{ Blok 3.2} \\
\hline 10 & Imunisasi & \multicolumn{2}{|c|}{ Blok 3.2} \\
\hline 11 & IPM 4 (Kasus Sensitif) & \multicolumn{2}{|c|}{ Blok 3.3} \\
\hline \multicolumn{4}{|c|}{ Tabel 2 Materi OSCE semester 6} \\
\hline No & \multicolumn{2}{|c|}{ Materi OSCE Semester 5} & $\begin{array}{c}\text { Blok Yang } \\
\text { Bersesuaian }\end{array}$ \\
\hline 1 & \multicolumn{2}{|c|}{ IPM 1 (kasus mata) } & Blok 3.4 \\
\hline 2 & \multicolumn{2}{|c|}{ IPM 2 (kasus THT) } & Blok 3.4 \\
\hline 3 & \multicolumn{2}{|c|}{ IPM 3 (kasus endokrin) } & Blok 3.5 \\
\hline 4 & \multicolumn{2}{|c|}{ IPM 4 (kasus saraf) } & Blok 3.6 \\
\hline 5 & \multicolumn{2}{|c|}{ IPM 5 (kasus kardiovaskular) } & Blok 3.5 \\
\hline 6 & \multicolumn{2}{|c|}{ IPM 6 (kasus respirasi) } & Blok 3.5 \\
\hline 7 & \multicolumn{2}{|c|}{ IPM 7 (kasus kulit) } & Blok 3.4 \\
\hline 8 & \multicolumn{2}{|c|}{ IPM 8 (kasus pencernaan) } & Blok 3.5 \\
\hline 9 & \multicolumn{2}{|c|}{ IPM 9 (kasus perkemihan) } & Blok 3.5 \\
\hline 10 & \multicolumn{2}{|c|}{ IPM 10 (kasus muskuloskeletal) } & Blok 3.6 \\
\hline
\end{tabular}

Nilai kemampuan diagnosis sebagai representasi dari kemampuan clinical reasoning pada ujian OSCE dilakukan rekapitulasi. Nilai clinical reasoning stasion OSCE 4 stasion IPM pada semester 5 dan 10 stasion IPM pada semester 6 merupakan nilai yang didapat dengan berdasarkan rubrik penilaian dengan nilai minimal 0 dan nilai maksimal 3. Rerata nilai kemampuan clinical 
reasoning pada masing-masing stasion OSCE dapat dilihat pada tabel 3. Rerata nilai kemampuan clinical reasoning mahasiswa tertinggi pada stasion IPM kasus ginekologi yaitu 2,43 Sedangkan nilai rerata kemampuan clinical reasoning terendah adalah pada IPM kasus pediatrik 2 yaitu 1,5 .

Tabel 3. Nilai kemampuan clinical reasoning OSCE semester 5 dan semester 6

\begin{tabular}{lc}
\hline \multicolumn{1}{c}{ Station OSCE } & $\begin{array}{c}\text { Nilai kemampuan } \\
\text { clinical reasoning }\end{array}$ \\
\hline Semester 5 & 2,43 \\
Kasus ginekologi & 1,54 \\
Kasus pediatrik 1 & 1,5 \\
Kasus pediatrik 2 & 1,87 \\
Kasus sensitive & \\
Semester $\mathbf{6}$ & 1,92 \\
Kasus mata & 2,24 \\
Kasus THT & 1,67 \\
Kasus kulit & 1,99 \\
Kasus endokrin & 1,90 \\
Kasus kardiovaskular & 1,90 \\
Kasus respirasi & 1,89 \\
Kasus pencernaan & 1,73 \\
Kasus perkemihan & 1,73 \\
Kasus muskuloskeletal & 2,04 \\
Kasus saraf & \\
\hline
\end{tabular}

Nilai rerata kemampuan clinical reasoning antar stasion tersebut selanjutnya dilakukan analisis uji beda untuk mengetahui adanya perbedaan kemampuan clinical reasoning mahasiswa antar kasus yang diberikan. Analisis statistik yang digunakan adalah analisis Kruskal Wallis dikarenakan sebaran data yang tidak normal. Hasil didapatkan bahwa terdapat perbedaan rerata nilai kemampuan clinical reasoning antar stasion OSCE baik pada stasion OSCE semester 5 maupun pada stasion OSCE semester 6 dengan nilai $p$ masing-masing 0,00 .

Pencapaian kemampuan clinical reasoning mahasiswa pada ujian OSCE dengan kasus klinis selanjutnya dianalisis korelasinya dengan kemampuan kognitif
Terdapat tiga kasus dengan pencapaian nilai rerata kemampuan clinical reasoning di atas 2 . Sementara 11 kasus lainnya rerata pencapaian mahasiswa kurang dari 2 . 
reasoning pada sembilan stasion OSCE

lainnya tidak memiliki korelasi dengan kemampuan mahasiswa pada ujian tulis

blok (Tabel 4).

Tabel 4. Korelasi nilai kemampuan clinical reasoning OSCE dengan nilai ujian tulis blok

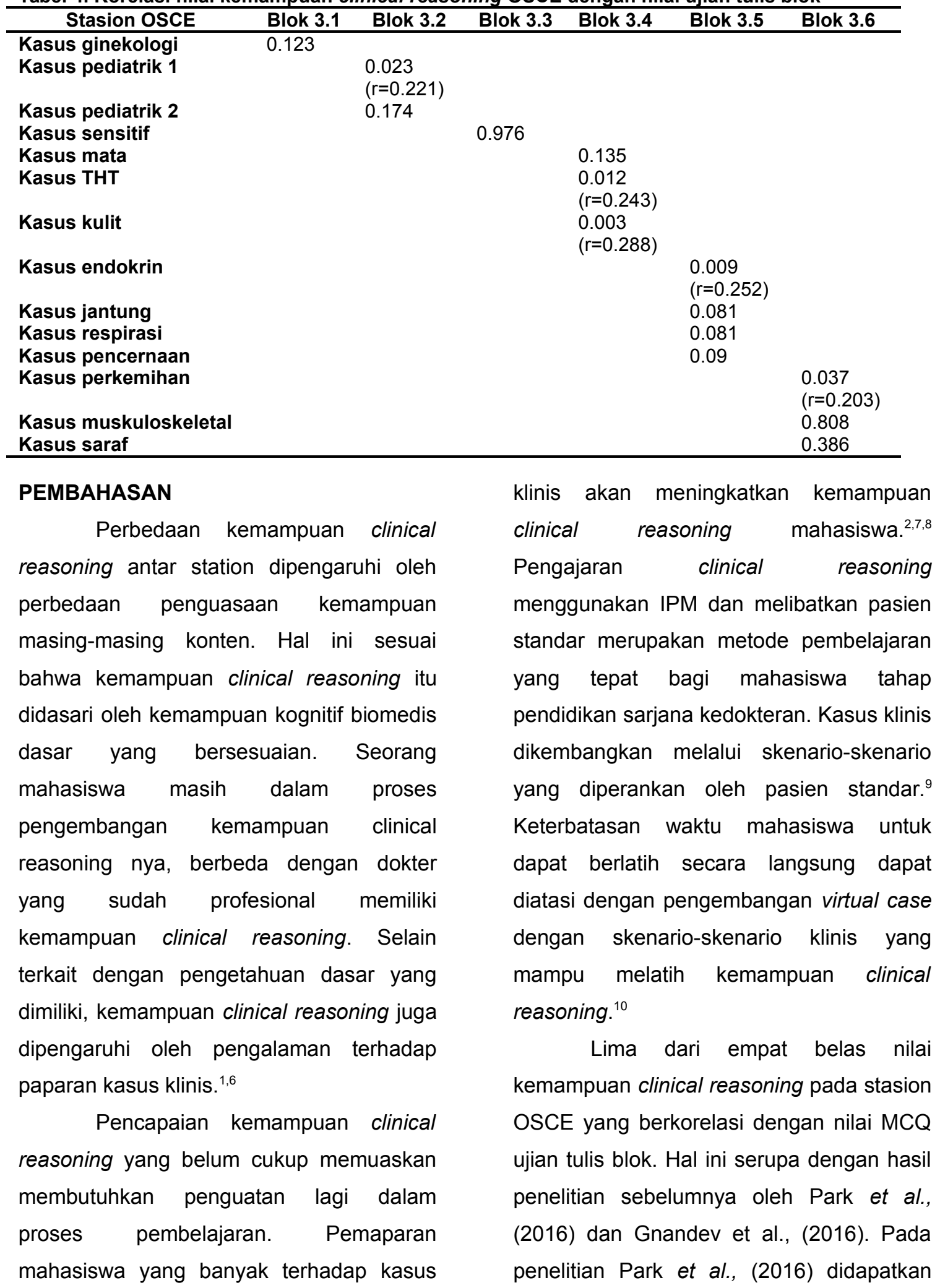


kemampuan clinical reasoning mahasiswa tidak berkorelasi dengan dengan nilai stasion OSCE dan kemampuan clinical reasoning tidak berkorelasi dengan pengetahuan klinis. Namun pada penelitian tersebut hanya menggunakan 4 kasus klinis yang dinilai kurang memberikan gambaran penguasaan clinical reasoning mahasiswa yang diteliti. ${ }^{11}$ Sedangkan pada peneltian oleh Gnandev et al., (2016) terdapat korelasi yang lemah antara nilai MCQ dengan nilai OSCE pada setting klinis Anestesiologi. Pada penelitian tersebut mencermati bahwa hendaknya kemampuan klinis teoritis akan menunjang keterampilan klinis yang baik. Namun pada penelitian tersebut melihat kelemahan dalam mengkorelasikan dua domain assessment yang berbeda. ${ }^{12}$

Penelitian yang dilakukan peneliti pada penelitian ini menggunakan sebagian dari nilai OSCE yaitu hanya pada aspek penilaian kemampuan diagnosis sebagai representasi dari kemampuan clinical reasoning mahasiswa pada tahun ketiga. Nilai tersebut dapat lebih mewakili gambaran kemampuan clinical reasoning mahasiswa, tidak dipengaruhi oleh domain keterampilan klinis lainnya seperti domain keterampilan prosedural ataupun pemeriksaan fisik.

Keterbatasan pada penelitian ini adalah pengamatan hanya dilakukan pada satu tahun ajaran dan pada satu periode mahasiswa. Evaluasi dan pengembangan terhadap proses pembelajaran maupun ujian OSCE yang menilai kemampuan clinical reasoning perlu dilakukan. Evaluasi dan pengembangan dapat dilakukan baik dari sisi proses pembelajaran, soal maupun rubrik penilaian.

\section{KESIMPULAN}

Hasil penelitian ini dapat disimpulkan bahwa kemampuan clinical reasoning mahasiswa kedokteran tahun ketiga pada ujian OSCE yang dinilai melalui kemampuan menegakkan diagnosis dari kasus klinis yang diberikan, belum memberikan gambaran kemampuan clinical reasoning yang memuaskan. Evaluasi dan pengembangan terhadap proses pembelajaran maupun ujian OSCE yang menilai kemampuan clinical reasoning perlu dilakukan. Evaluasi dan pengembangan dapat dilakukan baik dari sisi proses pembelajaran, soal maupun rubrik penilaian.

\section{DAFTAR PUSTAKA}

1. Bowen, J. L. (2006). Educational strategies to promote clinical diagnostic reasoning. New England Journal of Medicine, 355(21), 2217-2225.

2. Kassirer, J. P. (2010). Teaching clinical reasoning: case-based and coached. Academic Medicine, 85(7), 1118-1124.

3. Berger, A. J., Gillespie, C. C., Tewksbury, L. R., Overstreet, I. M., Tsai, M. C., Kalet, A. L., \& Ogilvie, J. B. (2012). Assessment of medical student clinical reasoning by "lay" vs physician raters: inter-rater reliability using a scoring guide in a multidisciplinary objective structured clinical examination. The American Journal of Surgery, 203(1), 81-86. 
4. Sim, J. H., Aziz, Y. F. A., Mansor, A., Vijayananthan, A., Foong, C. C., \& Vadivelu, J. (2015). Students' performance in the different clinical skills assessed in OSCE: what does it reveal?. Medical education online, 20.

5. Boshuizen, H., Vleuten, C. P., Schmidt, H. G., \& Machiels-Bongaerts, M. (1997). Measuring knowledge and clinical reasoning skills in a problem-based curriculum. Medical Education, 31(2), 115-121.

6. Woods, N. N. (2007). Science is fundamental: the role of biomedical knowledge in clinical reasoning. Medical education, 41(12), 1173-1177.

7. Eva, K. W. (2005). What every teacher needs to know about clinical reasoning. Medical education, 39(1), 98-106.

8. Rencic, J. (2011). Twelve tips for teaching expertise in clinical reasoning. Medical Teacher, 33(11), 887-892.

9. Barrows, H. S. (1993). An overview of the uses of standardized patients for teaching and evaluating clinical skills. AAMC. Academic Medicine, 68(6), 443-51.

10. Gesundheit, N., Brutlag, P., Youngblood, P., Gunning, W. T., Zary, N., \& Fors, U. (2009). The use of virtual patients to assess the clinical skills and reasoning of medical students: initial insights on student acceptance. Medical teacher, 31(8), 739-742.

11. Park, W. B., Kang, S. H., Myung, S. J., \& Lee, Y. S. (2015). Does Objective Structured Clinical Examinations Score Reflect the Clinical Reasoning Ability of Medical Students?. The American journal of the medical sciences, 350(1), 64-67.

12. Gnandev, P., Loh, K. Y., Nurjahan, M. I., Roland, S., \& Noor, A. R. (2016). Comparison Study on End-of-Posting OSCE Versus MCQ Scores in Anaesthesiology Posting, Taylor's University School of Medicine. In Assessment for Learning Within and Beyond the Classroom (pp. 391-395). Springer Singapore. 